\title{
AKTIVITAS SEHARI-HARI DAN KUALITAS HIDUP PASIEN GAGAL GINJAL KRONIK YANG MENJALANI TERAPI HEMODIALISA DI RUMAH SAKIT UMUM IMELDA PEKERJA INDONESIA MEDAN
}

\author{
Deddy Sepadha Putra Sagala, Wahyu Gunawan Sagala \\ Universitas Imelda Medan, Jl. Bilal No. 52 Kelurahan Pulo Brayan Darat I Kecamatan Medan Timur, \\ Medan - Sumatera Utara. \\ E-mail: deddyspsagala@gmail.com
}

\begin{abstract}
ABSTRAK
Pasien GGK mengalami gangguan fungsi ginjal sampai 90\% atau lebih, yang berakibat pada kurangnya kemampuan tubuh mempertahankan keseimbangan cairan dan elektrolit, fungsi sekresi, fungsi hormonal, serta mengakibatkan terjadinya uremia atau azotemia (Parson, Toffelmire \& Valack, 2006). Perhimpunan Nefrologi Indonesia (PERNEFRI) 2014, memperkirakan prevalensi GGK meningkat dar itahun 2011 sebesar 25.353 pasien menjadi 28.882. Dengan komposisi 55.77\% perempuan (16.108 pasien) dan 44,23\% laki-laki (12.774 pasien). Data ini meningkat karena ditahun 2015 terdapat 21.050 pasien baru dan 30.554 pasien aktif dari tahun sebelumnya yang rutin menjalani hemodialisa, dengan jumlah pasien terbanyak usia 45-64 tahun. Jenis Penelitian ini adalah Kuantitatif dengan desain korelasional dengan pendekatan cross sectional. Metode mengambilan sampel Non Probability Sampling dimana jumlah populasi 98 responden, dengan tehnik sampling purposive sampling, didapat sampel dalam penelitian ini berjumlah 79 responden. Pengumpulan data dilakukan menggunakan kuesioner yang terdiri dari 37 pertanyaan (Lawton and Brody Scale) untuk variabel aktifitas sehari-hari dan 26 kuesioner kualitas hidup WHOQOL-BREF, Tehnik pengukuran pertanyaan menggunakan skala Linkert, dalam bentuk kuesioner tertutup. Kuesioner diformulasikan dalam interval jawaban variabel menggunakan rumus Sturgers untuk menentukan kriteria jawaban responden serta mengetahui skor dan persentase jawaban. Dari hasil penelitian diketahui mayoritas dari 79 responden mengalami gangguan dalam pemenuhan aktivitas sehari-hari dalam kategori berat sebanyak 40 orang (50,6\%), Untuk kualias hidup ditemui mayoritas dari 79 responden memiliki kualitas hidup mayoritas buruk sebanyak 44 orang $(55,7 \%)$ serta dari hasil perhitungan statistik diperoleh nilai probabilitas (p) untuk hubungan Aktivitas sehari-hari bernilai $=0,851$, yang berarti tidak ada hubungan secara signifikan dengan kualitas hidup $(p>0.05)$.
\end{abstract}

Kata kunci : Aktifitas sehari-hari, Kualitas hidup, Hemodialisa

\section{ABSTRACT}

GGK patients experience impaired kidney function up to $90 \%$ or more, which results in a lack of the body's ability to maintain fluid and electrolyte balance, secretion function, hormonal function, and cause uremia or azotemia (Parson, Toffelmire \& Valack, 2006). The Indonesian Nephrology Association (PERNEFRI) in 2014 estimated the prevalence of GGK to increase in 2011 by 25,353 patients to $28,882$. With a composition of $55.77 \%$ women $(16,108$ patients) and $44.23 \%$ men (12,774 patients). This data is improved because in 2015 there were 21,050 new patients and 30,554 active patients from the previous year who routinely undergo modernization, with the number of patients 45-64 years old. This type of research is quantitative with correlational design with cross sectional approach. The method of taking a Non Probability Sampling sample in which the population of 98 respondents, using purposive sampling technique, obtained samples in this study amounted to 79 respondents. Data collection was carried out using a questionnaire consisting of 37 questions (Lawton and Brody Scale) for daily activity variables and 26 WHOQOL-BREF quality of life questionnaires, Question measurement techniques using Linkert scale, in the form of a closed questionnaire. The questionnaire was formulated in a variable answer interval using the Sturgers formula to determine the respondent's answer criteria and find out the score and percentage of answers. From the results of the study note that the majority of 79 respondents experienced disturbances in fulfilling daily activities in the heavy category of 40 people (50.6\%). For the quality of life found the majority of 79 respondents had a poor majority of quality of life of 44 people $(55.7 \%)$ as well as the results of statistical calculations obtained the probability value ( $p)$ for the relationship of daily activities value $=0.851$, which means there is no significant relationship with quality of life ( $p>0.05)$.

Keywords: Daily activities, Quality of life, Hemodialysis 


\section{PENDAHULUAN}

Penyakit gagal ginjal kronis (GGK), merupakan suatu sindrome klinis yang disebabkan penurunan dari fungsi ginjal yang sifatnya menahun, berlangsung progresif dan cukup lanjut, mengakibatkan laju filtrasi glomerator kurang dari $50 \mathrm{ml} / \mathrm{menit}$. Gagal ginjal kronik juga dapat diartikan suatu penyakit ginjal dengan tahap akhir yang mengakibatkan terjadinya gangguan fungsi ginjal menahun bersifat progresif dan irreversible, berakibat menurunnya kemampuan tubuh dalam mempertahankan metabolisme serta keseimbangan cairan elektrolit (Rendy \& Margareth, 2012).

Pasien GGK akan mengalami kehilangan fungsi ginjal sampai $90 \%$ atau lebih, sehingga kemampuan tubuh untuk mempertahankan keseimbangan cairan dan elektrolit akan terganggu, fungsi sekresi, fungsi hormonal akan terganggu serta mengakibatkan kondisi uremia atau azotemia (Parson, Toffelmire \& Valack, 2006).

GGK merupakan ancaman global bagi populasi secara umum, khususnya bagi negara-negara berkembang. Menurut data WHO (2011) dalam Zachariah dan Ghopalcrisnan (2014) memperkirakan secara global bahwa penyakit gagal ginjal kronis merupakan penyebab utama kematian diurutan ke-12 dan urutan ke-17 penyebab kecacatan. Hill et al., (2016) menyatakan bahwa prevalensi global GGK sebesar 13.4\%, Data Kementerian Kesehatan menunjukkan bahwa prevalensi GGK di indonesiasekitar $0.2 \%$ dengan prevalensi kelompok umur $\geq$ 75 tahun sebanyak $0.6 \%$, pada kelompok umur ini kejadian GGK lebih tinggi daripada kelompok umur ainnya (Riskesdas, 2013). Angka ini lebih rendah jika dibandingkan dengan prevalensi GGK di negara lain, sementara itu penelitian Perhimpunan Nefrologi Indonesia (PERNEFRI) di tahun 2015 terdapat 21.050 jumlah pasien baru dan 30.554 jumlah pasien aktif dari tahun sebelumnya yang rutin menjalani hemodialisa, dengan proporsi pasien terbanyak pada kategori usia 45 -64 tahun.

$$
\text { Smeltzer dan Bare (2002) }
$$

mengungkapkan bahwa untuk mengatasi masalah GGK dapat dilakukan berbagai terapi, salah satunya dengan terapi hemodialisis. Terapi ini merupakan tindakan mengganti sebagian fungsi dari organ ginjal. Terapi ini dilakukan rutin pada penderita
GGK stadium V. Untuk frekuensi hemodialisis dapat bervariasi tergantung banyaknya fungsi ginjal yang tersisa, rerata penderita menjalani hemodialisis sekirat dua kali dalam seminggu dengan waktu pelaksanaan setidaknya tiga sampai empat jam tiap sekali tindakan terapi (Melo, Ribeiro \& Costa, 2015).

Pasien hemodialisa memiliki gangguan pemenuhan perawatan diri (self-care deficit) yang berdampak terhadap kemampuan penderita untuk melakukan aktivitas-seharihari seperti kemampuan perawatan fisik, pemenuhan asupan cairan dan nutrisi, regiment terapi pengobatan, perawatan akses vaskular, kemampuan berinteraksi, pemanfaatan fasilitas kesehatan, melaporkan gejala yang muncul dan juga perilaku kesehatan. Gangguan perawatan diri seharihari tersebut akan berdampak terhadap pemenuhan kemampuan aktivitas sehari-hari pasien seperti makan, minum, mandi, berpakaian, berdandan, kebersihan diri, toileting dan mobilitas (Curtin, Mapes, Schatell \&Hudson, 2005; Cook \& Jassal, 2008). Menurut Cook dan Jassal (2008) bahwa dari 168 responden yang diteliti, responden yang mengalami ketergantungan terhadap pekerjaan rumah tangga (80\%), belanja $(81 \%)$, mencuci $(80 \%)$, memasak $(68 \%)$, menaiki tangga (52\%), mandi (68\%), transportasi (49\%) dan ambulasi atau pergerakan (29\%).

Pasien hemodialisa yang mengalami gangguan aktivitas sehari-hari akan berdampak terhadap kesehatan fisik, mobilisasi dan perlunya perawatan berulang dalam jangka panjang akibat anemia, uremia, miopati, gangguan tulang dan mineral. Kebutuhan mobilisasi yang tidak terpenuhi dapat menjadi salah satu faktor penyebab kematian pada pasien hemodialisa. Keterbatasan aktivitas sehari-hari pasien hemodialisa dapat mengakibatkan terjadinya stress, frustasi, depresi, penurunan daya ingat, mudah tersinggung dan sesitif (Demarco et al., 2012; Gomes et al., 2015; Rulli \& Rusli, 2001).

Minimnya informasi yang diperoleh dari petugas kesehatan selama terapi, mengakibatkan kurangnya informasi dan pengetahuan pasien dan keluarga tentang perawatan diri sehari-hari akibat penyakit dan proses terapi yang dijalaninya (Taylor \& Renpenning, 2011). Padahal pentingnya 
perawatan diri pada pasien hemodialisa sebagai salah satu pemenuhan aktifitas dalam peningkatan kualitas hidup sudah menjadi perhatian di dunia.

Thornton dan Lingertfelt (2011) mengatakan bahwa edukasi perawatan diri (self-care) secara signifikan dapat meningkatkan pengetahuan dan kemandirian serta meningkatkan kemampuan pasien dalam melakukan perawatan sehari-hari di rumah seprti manajemen diri untuk pemenuhan kebutuhan nutrisi dan mengikuti program terapi pengobatan. Penelitian sebelumnya yang berjudul "Pengaruh Tindakan Hemodialisa Terhadap Perubahan Tekanan Darah Pada Klien Gagal Ginjal Kronik Di Rumah Sakit Imelda Medan Tahun 2018" bahwa terdapat hubungan tindakan Hemodialisa dengan Perubahan Tekanan Darah pada Pasien Pasca Hemodialisis (Noradina, 2018).

Penelitian lain yang berjudul Hubungan Dukungan Keluarga Dengan Aktifitas SehariHari Pasien Gagal Ginjal Kronik Yang Mengalami Hemodialisa Di RSU IPI Medan Tahun 2018 menyatakan bahwa pasien yang memiliki keyakinan, harapan dan keingian yang kuat bisa menumbuhkan dukungan keluarga yang positif pemberian edukasi pada pasien gagal ginjal kronik yang dilakukan terapi hemodialisa agar pasien dapat menjalani terapi sesuai jadwal (Sagala \& Sitompul, 2019).

Berdasarkan penelitian yang berjudul "Pengaruh Pemberian Konseling Dengan Tingkat Kecemasan Pada Pasien Yang Menjalani Hemodialisis Di Rumah Sakit Kota Medan" menyatakan bahwa terdapat pengaruh pemberian konseling dengan tingkat kecemasan pasien hemodialisa (Silaen, 2018).

Teori Orem dalam Tomey dan Alligood (2006) mengatakan bahwa pasien gagal ginjal kronis yang menjalani terapi hemodialisa akan dapat mempertahankan kesehatannya setelah banyak mengetahui tentang penyakit serta gejala yang dialaminya, hal ini akan dapat terjadi lewat salah satu intervensi non farmakologis yaitu edukasi kesehatan tentang pengolahan gaya hidup serta memberikan sentuhan dan motivasi agar pasien tetap dapat menjaga dirinya sendiri atau dapat melakukan perawatan dirinya sendiri (self-care).

Berdasarkan wawancara yang dilakukan oleh penulis pada bulan maret tahun 2019 terhadap beberapa orang perawat di Rumah
Sakit Umum Imelda Pekerja Indonesia Medan bahwa pasien gagal ginjal kronis yang menjalani hemodialisa tahun 2019 per bulan rata - rata 352 orang secara reguler dengan jumlah alat hemodialisis sebanyak 16 buah, beberapa diantaranya mengalami keterbatasan kemampuan dalam melakukan pemenuhan aktivitas sehari-hari seperti takut untuk berjalan ke ruang unit hemodialisa saat mau melakukan terapi meskipun edukasi sudah diberikan sebelumnya, hal ini tentunya akan mempengaruhi kualitas hidup dari klien. Pemahaman tentang pemenuhan aktivitas sehari-hari sangat penting untuk tetap menjaga serta meningkatkan kualitas hidupnya dalam menjalani proses terapi serta pelaksanaan asuhan keperawatan, yang holistik guna meningkatkan kepercayaan individu untuk meningkatkan kualitas hidupnya.

Berdasarkan uraian tersebut peneliti tertarik meneliti tentang hubungan aktivitas sehari-hari dengan kualitas hidup pasien gagal ginjal kronik yang menjalani terapi hemodialisa di Rumah Sakit Umum Imelda Pekerja Indonesia Medan.

\section{METODE PENELITIAN}

Adapun tujuan penelitian ini untuk menganalisis hubungan aktivitas sehari-hari dengan kualitas hidup pasien gagal ginjal kronik yang menjalani terapi hemodialisa di Rumah Sakit Umum Imelda Pekerja Indonesia Medan dari bulan Maret - April 2019. Penelitian ini merupakan penelitian kuantitatif dengan desain korelasional. Pendekatan dalam penelitian ini adalah cross sectional untuk menganalisis hubungan antara variabel independen yaitu aktivitas sehari-hari dengan variabel dependen yaitu kualitas hidup pada pasien gagal ginjal kronik yang menjalani hemodialisa yang diukur dalam satu kali pengukuran menggunakan kuesioner aktivitas sehari-hari (Lawton and BrodyScale) dan Kuesioner kualitas hidup World Health Organization Quality of LifeBREF (WHOQOL-BREF). Populasi penelitian ini seluruh pasien GGK yang mengikuti hemodialisa di Rumah Sakit Umum Imelda Pekerja Indonesia Medan sebanyak 98 orang. Teknik sampling yang digunakan dalam penelitian ini adalah nonprobability sampling dengan jenis purposive sampling didapatkan jumlah sampel yang digunakan dalam penelitian ini sebanyak 79 responden. Analisis data 
penelitian ini dilakukan dengan univariat dan bivariat. untuk menguji atau melihat hubungan antar dua variabel dilakukan analisis data dengan analisa Chi-Square.

\section{HASIL}

Tabel 1. Karakteristik pasien gagal ginjal kronis yang menjalani hemodialisa berdasarkan usia, jenis kelamin, pendidikan, status pernikahan, suku bangsa, status pekerjaan, penghasilan keluarga, biaya pengobatan, lama menjalani hemodialisa, dan siklus hemodialisa di RSU Imelda Pekerja Indonesia Medan tahun $2019(\mathrm{n}=79)$

\begin{tabular}{|c|c|c|c|}
\hline No & Karakteristik & $\mathbf{f}$ & $\begin{array}{c}\text { Persentase } \\
(\%)\end{array}$ \\
\hline \multirow[t]{4}{*}{1} & Usia (Tahun) & & \\
\hline & 26-44 (usia dewasa) & 9 & 11,4 \\
\hline & $\begin{array}{l}45-59 \text { (usia } \\
\text { pertengahan) }\end{array}$ & 48 & 60,8 \\
\hline & 60-74 (lanjut usia) & 22 & 27,8 \\
\hline \multirow[t]{3}{*}{2} & Jenis Kelamin & 2 & \\
\hline & Laki-laki & 25 & 31,6 \\
\hline & Perempuan & 54 & 68,4 \\
\hline \multirow[t]{5}{*}{3} & Pendidikan & & \\
\hline & $\mathrm{SD}$ & 22 & 27,8 \\
\hline & SMP & 18 & 22,8 \\
\hline & SMA & 36 & 45,6 \\
\hline & PT & 3 & 3,8 \\
\hline \multirow[t]{4}{*}{4} & Status Pernikahan & & \\
\hline & Menikah & 59 & 74,7 \\
\hline & Janda/Duda & 16 & 20,3 \\
\hline & BelumMenikah & 4 & 5,1 \\
\hline \multirow[t]{4}{*}{5} & SukuBangsa & - & 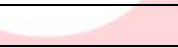 \\
\hline & Batak & 41 & 51,9 \\
\hline & Jawa & 32 & 40,5 \\
\hline & Melayu & 6 & 7,6 \\
\hline \multirow[t]{3}{*}{6} & Status Pekerjaan & & \\
\hline & Bekerja & 36 & 45,6 \\
\hline & Tidak bekerja & 43 & 54,4 \\
\hline \multirow[t]{3}{*}{7} & Penghasilan Keluar & & \\
\hline & $\begin{array}{l}\leq \mathrm{Rp} 2.750 .000 \\
(\leq \mathrm{UMK})\end{array}$ & 66 & 83,5 \\
\hline & $\begin{array}{l}>\operatorname{Rp} 2.750 .000 \\
(>\mathrm{UMK})\end{array}$ & 13 & 16,5 \\
\hline \multirow[t]{3}{*}{8} & BiayaPengobatan & & \\
\hline & BPJS & 76 & 96,2 \\
\hline & Asuransi Lain & 3 & 3,8 \\
\hline \multirow[t]{3}{*}{9} & Lama Menjalani H & odia & \\
\hline & 3-6 Bulan & 56 & 70,9 \\
\hline & $>6$ Bulan & 23 & 29,1 \\
\hline \multirow[t]{4}{*}{10} & SiklusHemodialisa & & \\
\hline & $3 \mathrm{X}$ perminggu & 22 & 27,8 \\
\hline & $2 \mathrm{X}$ perminggu & 55 & 69,7 \\
\hline & $1 \mathrm{X}$ perminggu & 2 & 2,5 \\
\hline \multicolumn{2}{|c|}{ Total } & 79 & 100 \\
\hline
\end{tabular}

hemodialisa lebih setengah berada pada kategori usia 45-59 tahun (usia pertengahan) sebanyak 48 orang $(60.8 \%)$. Berdasarkan jenis kelamin hamper tiga perempat pasien gagal ginjal kronis yang menjalani hemodialisa adalah perempuan sebanyak 54 orang $(68.4 \%)$. Berdasarkan pendidikan hamper setengah pasien gagal ginjal kronis yang menjalani hemodialisa adalah lulusan SMA sebanyak 36 orang (45.6\%). Berdasarkan status pernikahan hampir tiga perempat pasien gagal ginjal kronis yang menjalani hemodialisa adalah menikah sebanyak 59 orang $(74.7 \%)$. Berdasarkan suku bangsa lebih dari setengah pasien gagal ginjal kronis yang menjalani hemodialisa adalah bersuku batak sebanyak 41 orang $(51.9 \%)$. Berdasarkan status pekerjaan lebih dari setengah pasien gagal ginjal kronis yang menjalani hemodialisa adalah tidak bekerja, yakni sebanyak 43 orang (54.4\%). Berdasarkan penghasilan keluarga lebih dari tiga perempat pasien gagal ginjal kronis yang menjalani hemodialisa adalah berpenghasilan $\leq \mathrm{Rp} 2.750 .000$ ( $\leq \mathrm{UMK}$ ) sebanyak 66 orang $(83.5 \%)$. Berdasarkan biaya pengobatan hamper seluruhnya pasien gagal ginjal kronis yang menjalani hemodialisa adalah BPJS sebanyak 76 orang $(96.2 \%)$. Berdasarkan lama menjalani hemodialisa hamper tiga perempat pasien gagal ginjal kronis yang menjalani hemodialisa dengan interval 3-6 bulan sebanyak 56 orang $(70.9 \%)$, dan berdasarkan siklus hemodialisa lebih dari setengah pasien gagal ginjal kronis yang menjalani hemodialisa adalah $2 \mathrm{X}$ perminggu sebanyak 55 orang (69.7\%).

Tabel 2. Aktivitas sehari-hari pasien gagal ginjal kronis yang menjalani hemodialisa di

RSU Imelda Pekerja Indonesia Medan

\begin{tabular}{cccc}
\hline No & $\begin{array}{c}\text { Aktivitas sehari- } \\
\text { hari }\end{array}$ & F & $\begin{array}{c}\text { Persentase } \\
(\mathbf{\%})\end{array}$ \\
\hline $\mathbf{1}$ & Ringan & 3 & 3,8 \\
\hline $\mathbf{2}$ & Sedang & 36 & 45,6 \\
\hline $\mathbf{3}$ & Berat & 40 & 50,6 \\
\hline & Total & $\mathbf{7 9}$ & $\mathbf{1 0 0}$ \\
\hline
\end{tabular}

Dari tabel 2 diketahui bahwa mayoritas dari 79 responden mengalami gangguan dalam pemenuhan aktivitas sehari-hari dalam kategori berat sebanyak 40 orang $(50,6 \%)$, sedang 36 orang $(36 \%)$ dan hanya 3 orang $(3,8 \%)$ dalam kategori bantuan ringan. 
Tabel 3. Kualitas hidup pasien gagal ginjal kronis yang menjalani hemodialisa di RSU Imelda Pekerja Indonesia Medan

\begin{tabular}{cccc}
\hline No & $\begin{array}{c}\text { Aktivitas sehari- } \\
\text { hari }\end{array}$ & F & $\begin{array}{c}\text { Persentase } \\
(\mathbf{\%})\end{array}$ \\
\hline $\mathbf{1}$ & Baik & 35 & 44,3 \\
\hline $\mathbf{2}$ & Buruk & 44 & 55,7 \\
\hline & Total & $\mathbf{7 9}$ & $\mathbf{1 0 0}$ \\
\hline
\end{tabular}

Dari Tabel 3 diketahui bahwa mayoritas dari 79 responden memiliki kualitas hidup mayoritas buruk sebnyak 44 orang $(55,7 \%)$ sedangkan untuk kualitas hidup baik dalam nilai yang tidak terlalu signifikan sebanyak 35 orang $(44,3 \%)$.

Tabel 4. Tabulasi silang aktifitas sehari-hari dengan kualitas hidup pasien gagal ginjal kronis yang menjalani hemodialisa di RSU Imelda Pekerja Indonesia Medan

\begin{tabular}{cccccc}
\hline \multirow{2}{*}{$\begin{array}{c}\text { Variabel Aktifitas } \\
\text { Sehari-hari }\end{array}$} & \multicolumn{2}{c}{$\begin{array}{c}\text { Kualitas } \\
\text { Hidup }\end{array}$} & RP & $\boldsymbol{p}$ \\
\cline { 2 - 3 } & Baik & Buruk & & \\
\hline \multirow{2}{*}{ Ringan } & 1 & 2 & & \\
& $1,3 \%$ & $2,5 \%$ & & \\
\hline \multirow{2}{*}{ Sedang } & 17 & 19 & & \multirow{2}{*}{0,851} \\
& $21,5 \%$ & $24,1 \%$ & & \\
\hline \multirow{2}{*}{ Berat } & 17 & 23 & & \\
& $21,5 \%$ & 29,1 & & \\
\hline Total & $\mathbf{3 5}$ & $\mathbf{4 4}$ & & \\
\hline
\end{tabular}

Dari tabel 4 diketahui bahwa mayoritas dari 79 responden pemenuhan aktivitas sehari-hari dalam kategorik ketergantungan berat dengan kualitas hidup buruk sebanyak 23 orang $(29,1 \%)$ dan pemenuhan aktivitas sehari-hari dalam kategorik ketergantungan berat dengan kualitas hidup baik sebanyak 17 responden $(21,5 \%)$, hal ini tidak terlalu signifikan dan minoritas hanya 1 orang dalam ketergantungan ringan dalam pemenuhan aktifitas sehari-hari dengan kualitas hidup baik $(1,3 \%)$, sedangkan dari hasil perhitungan statistik diperoleh nilai probabilitas $(p)$ untuk hubungan Aktivitas sehari-hari bernilai = 0,851 , yang berarti tidak ada hubungan secara signifikan dengan kualitas hidup $(p>0.05)$. Menunjukkan tidak ada hubungan antara aktifitas sehari-hari dengan kualitas hidup pasien gagal ginjal kronis yang menjalan ihemodialisa di RSU Imelda Pekerja Indonesia Medan.

PEMBAHASAN

Aktivitas sehari-hari pasien gagal ginjal kronis yang menjalani hemodialisa di RSU Imelda Pekerja Indonesia Medan
Mayoritas responden mengalami ketergantungan berat dalam pemenuhan aktivitas sehari-hari dikaitkan dengan usia mayoritas responden lebih setengah berada pada kategori usia usia pertengahan, jenis kelamin hamper tiga perempat pasien gagal ginjal kronis yang menjalani hemodialisa adalah perempuan, pendidikan hampir setengah pasien gagal ginjal kronis yang menjalani hemodialisa adalah lulusan SMA serta berdasarkan penghasilan keluargal ebih dari tiga perempat pasien gagal ginjal kronis yang menjalani hemodialisa adalah berpenghasilan $\leq$ Rp 2.750 .000 ( $\leq$ UMK) dan yang lebih memperberat lagi adalah berdasarkan lama menjalani hemodialisa hamper tiga perempat pasien gagal ginjal kronis yang menjalani hemodialisa dengan interval 3-6 bulan dan berdasarkan siklus hemodialisa lebih dari setengah pasien gagal ginjal kronis yang menjalani hemodialisa adalah $2 \mathrm{X}$ perminggu tentunya hal ini akan mempengaruhi kondisi fisik dalam pemenuhan aktivitas sehari-hari pasien.

Kualitas hidup pasien gagal ginjal kronis yang menjalani hemodialisa di RSU Imelda Pekerja Indonesia Medan

Mayoritas responden memiliki kualitas hidup buruk sedangkan untuk kualitas hidup sedang dalam nilai yang tidak terlalu signifikan dengan kualitas hidup buruk, menurut asumsi peneliti kualitas hidup yang dimiliki pasien gagal ginjal kronis yang menjalani hemodialisa di RSU Imelda Pekerja Indonesia Medan mayoritas atau lebih dari setengah memiliki kualitas hidup buruk yang akan berpengaruh terhadap pemenuhan perawatan diri (self-care deficit) yang berdampak terhadap kemampuan penderita untuk melakukan aktivitas-seharihari seperti kemampuan perawatan fisik, pemenuhan asupan cairan dan nutrisi, regiment terapi pengobatan, perawatan akses vaskular, kemampuan berinteraksi, pemanfaatan fasilitas kesehatan, melaporkan gejala yang muncul dan juga perilaku kesehatan.

Hubungan aktifitas sehari-hari dengan kualitas hidup pasien gagal ginjal kronis yang menjalani hemodialisa di RSU Imelda Pekerja Indonesia Medan

Berdasarkan analisis data tabulasi silang antara aktifitas sehari-hari dengan kualitas hidup responden mayoritas lebih dari seperempat responden dalam pemenuhan 
aktivitas sehari-hari pada kategorik ketergantungan berat dengan kualitas hidup buruk disusul hampir seperempat responden dalam pemenuhan aktivitas sehari-hari pada kategorik ketergantungan berat dengan kualitas hidup baik dan minoritas hanya 1 orang dalam ketergantungan ringan dalam pemenuhan aktifitas sehari-hari dengan kualitas hidup baik, hal membuktikan bahwa tidak terlalu signifikan hubungan aktifitas sehari-hari dengan kualitas hidup sedangkan dari hasil perhitungan statistik diperoleh nilai probabilitas $(p)$ untuk hubungan Aktivitas sehari-hari bernilai $=0,851$, yang berarti tidak ada hubungan secara signifikan dengan kualitashidup $(p>0.05)$. Menunjukkan tidak ada hubungan antara aktifitas sehari-hari dengan kualitas hidup pasien gagal ginjal kronis yang menjalani hemodialisa di RSU Imelda Pekerja Indonesia Medan.

Menurut asumsi peneliti hal ini dapat terjadi karena ada banyak faktor yang dapat mempengaruhi kualitas hidup dari pasien GGK yang menjalani/hemodialisa selain pemenuhan aktifitas fisik (domain kesehatan fisik dan fungsinya), domain sosial dan ekonomi, domain psikologis, spiritual, dan domain keluarga/lingkungan (Ibrahim Kusman, Taboonpong, S., \& Nilmanat, 2009).

Penderita GGK yang menjalani terapi hemodialisa dalam jangka panjang sering mengalami ansietas berat dikarenakan sakit yang kronis serta ketakutan pada kematian. Selain itu, pasien juga mengalami masalah yang lain terkait kondisinya, diantaranya masalah finansial, kesulitan mempertahankan pekerjaan, hilang dorongan seksual serta impotensi dan hal ini akan mempengaruhi kualitas hidup pasien (Smeltzer \& Bare, 2002).

Dukungan dari semua anggota keluarga terutama pasangan sangat berperan dalam pengambilan keputusan dan strategi ketahanan hidup dalam mengelola emosional (dukungan emosional); memberikan inspirasi \& motivasi dukungan penilaian); memberikan dukungan informasi tentang kesehatan, gaya hidup, diet; dan juga mendukung penyediaan fasilitas (dukungan instrumental) sangat membantu bagi penderita gagal ginja lkronis yang sedang menjalani pengobatan dan akan membantu untuk meningkatkan ketahanan hidup pasien tersebut (Muhamad, Afshari, \& Kazilan, 2011).

\section{KESIMPULAN}

Hasil perhitungan statistik diperoleh nilai probabilitas $(p)$ untuk hubungan Aktivitas sehari-hari bernilai $=0,851$, yang berarti tidak ada hubungan secara signifikan dengan kualitas hidup $(p>0.05)$. Menunjukkan tidak ada hubungan antara aktifitas sehari-hari dengan kualitas hidup pasien gagal ginjal kronis yang menjalani hemodialisa di RSU Imelda Pekerja Indonesia Medan.

\section{DAFTAR PUSTAKA}

Bahadori, M., Ghavidel, F., Mohammadzadeh, S., \& Ravangard, R. (2014). The Effects of an Interventional Program Based on Self Care Model on Health-Related Quality of Life Outcomes in Hemodialysis Patients. Journal of Education and Health Promotion. Volume 4(Nov 2014).

Baraz,S., Rostami,M., Vardanjani,A.T., Masoudi,R., Rabiei,L., \& Vardanjani, S.A.E. (2012). The effect of self-care educational program on quality of life of elderly people in Ahvaz, Iran. Indian Journal of Science and Technology: ISSN: 0974-6846.Vol 5(10).

Brunner \& Suddarth. (2001). Keperawatan medikal bedah. (ed. 8. vol.1-2). Jakarta: EGC.

Cook, W.L., \& Jassal, S.V. (2008). Functional Drpendences Among The Elderly On Hemodialysis. Journal of International Society Of Nefrology 73 (7), 1289-1295.

Curtin, R.B., Mapes, D.I., Schatell, D., \& Burrows-Hudson, S. (2005). Self Mangement in Patients With End Stage Renal Desease. Exploring Domains and Dimenstion Neprologi Nursing Journal 32(4), 389-395.

Curtin, R.B., Walters, B.A., Schatell, D., Phennell, P., Wise, M., \& Klicko, K. (2008). Self Efficacy and Self Management Behaviors in Patinets Chronic Kidney Desease. Advances in Chronic Kidney Desease, 15(2) 191-205

Demarco, M.A.M., Law, A., Wang, J.M.G., Gimenez, L., Jaar, B.G., Waltson, J.D., \& Sagev, D.L. (2012). Activity of Daily Livings Mortality: Better Prediction Using Metrics of Aging. HHS Public Acces 60(10). 1981-1982. 
Indonesian Renal Registry (IRR). (2014). $5^{\text {th }}$ Report of Indonesia Renal Registry. Perhimpunan Nefrologi Indonesia (PERNEFRI).

Ibrahim Kusman, Taboonpong, S., \& Nilmanat. (2009). Coping and quality of life among indonesians undergoing hemodialysis. Vol. 13(2). Thai Journal of Nursing Research, 13(2) 109-117.

Ignatavicius, D., \& Workman, M.L. (2013). Medical surgical nursing: Patientcentered collaborative care. (Edisi 7). Elsevier Saunders.

Noradina. (2018). PENGARUH TINDAKAN HEMODIALISA TERHADAP PERUBAHAN TEKANAN DARAH PADA KLIEN GAGAL GINJAL KRONIK DI RUMAH SAKIT IMELDA MEDAN TAHUN 2018. Jurnal Ilmiah Keperawatan Imelda, 4(2), 132-138. http://jurnal.uimedan.ac.id/index.php/JU RNALKEPERAWATAN/article/view/2 95/298

Sagala, D. S. P., \& Sitompul, M. R. A. (2019). HUBUNGAN DUKUNGAN KELUARGA DENGAN AKTIFITAS SEHARI-HARI PASIEN GAGAL GINJAL KRONIK YANG MENGALAMI HEMODIALISA DI RSU IPI MEDAN TAHUN 2018. Jurnal Ilmiah Keperawatan Imelda, 5(1), 1219.

http://jurnal.uimedan.ac.id/index.php/JU RNALKEPERAWATAN/article/view/3 $02 / 305$

Silaen, H. (2018). PENGARUH PEMBERIAN KONSELING DENGAN TINGKAT KECEMASAN PADA PASIEN YANG MENJALANI HEMODIALISIS DI RUMAH SAKIT KOTA MEDAN. Jurnal Ilmiah Keperawatan Imelda, 4(1), 52-57. http://jurnal.uimedan.ac.id/index.php/JU RNALKEPERAWATAN/article/view/2
$84 / 287$

Parson, T.L., Toffelmire, E.B., Valack, C.E. (2006). Exercise Training During Hemodialysis Improves Dialysis Efficacy and Phsycal Performance. Arch Phys Med Rehabilitation.;87: 680687.

Polit, D.F., \& Beck, C.T. (2012). Nursing research: Generation and assesing evidance for nursing practice. (9 th. Ed.). Philadelphia, F.A.: Lippincott Williams \& Wilkins.

Rendy, C.M, \& Margareth, T.H. (2012). Asuhan keperawatan medikal bedah penyakit dalam. Yogyakarta: Nuha Medika.

Smeltzer, S.C., \& Bare, B.G. (2002). Buku Ajar keperawatan medikal bedah Brunner \& Suddarth. (Edisi 8). Jakarta: ECG.

Taylor, S.G., \& Renpenning, K. (2011). Self Care science, Nursing Theory and Evidance Based Practice Theory. Newyork: Springer Publishing Company.

Thornton K., Lingerfelt, KL. (2011).An educational project for patients on hemodialysis to promote selfmanagement behaviors of end stage renal disease education.Journal of Nefrology Nursing: 38 (6) 383-8.

Tomey, A. M., \& Alligood, M.R. (2006). Nursing Theory and Their Work. $\left(6^{\text {th }}\right.$ ed). St.Louis: Mosby Elsevier.

WHO. (1997). Quality of life-BREF. Diakses dari http://www.eho.int/substance abuse/research tools/whoqolbref/en. pada 07 April 2018.

Zachariah, L.M.S.\& Gopalkrishnan, S. (2014). Impact of music therapy during hemodialysis on selescted physiological paramaters of patients undergoing Hemodialysis in selected Hospitals. Interventional Journal of Comperhensive Nursing. Volume I. 